\title{
Use of Foley's catheter balloon tamponade to control placental site bleeding resulting from major placenta previa during cesarean section
}

\author{
Mohammed Khairy Ali, MD, ${ }^{1}$ Ahmed M. Abbas, MD, ${ }^{1}$ Ahmed Y. Abdelbadee, MS, ${ }^{1}$ \\ Sherif A. Shazly, MS, ${ }^{1}$ Ahmed M. AbdelMagied, MD ${ }^{1}$
}

Keywords: Balloon tamponade, cesarean section, Foley's catheter, placenta previa, postpartum hemorrhage.

\begin{abstract}
Aim: To evaluate the effect of 2-way Foley's catheter balloon tamponade on controlling immediate postpartum hemorrhage $(P P H)$ in cases of major placenta previa during cesarean section (CS).

Methods: We evaluated women with placenta previa from May to November 2015. Women with immediate $\mathrm{PPH}$ during $\mathrm{CS}$ due to major placenta previa were managed by 2-way Foley's catheter balloon tamponade when medical treatment failed, and before any surgical intervention.
\end{abstract}

Results: Twenty patients, had major placenta previa, were delivered by elective CS and complicated by immediate PPH. Three placenta accreta patients (15\%) underwent hysterectomy, 17 (85\%) were managed by the 2-way Foley's catheter balloon tamponade. In two patients, Foley's catheter balloon failed to control bleeding and hysterectomy was done immediately. However, Foley's catheter balloon successfully treated the remaining 15 patients. The median bleeding during the operation was 1522.5 ( \pm 619.29$) \mathrm{ml}$. None of them presented complications related to this procedure or required any further invasive surgery.

Conclusion: The 2-way Foley's catheter tamponade could be an option to control immediate postpartum hemorrhage resulting from major placenta previa during the cesarean section. This method is simple, cheap, nearly non-invasive and should be considered to reduce the risk of peripartum hysterectomy.

${ }^{1}$ Women Health Hospital, Assiut, Egypt

\section{Introduction}

Postpartum hemorrhage $(\mathrm{PPH})$ is defined as loss of more than $500 \mathrm{ml}$ of blood after delivery ${ }^{1}$ Loss of more than $1000 \mathrm{ml}$ of blood is considered physiologically significant and can affect the hemodynamic state. Postpartum hemorrhage is the most common cause of maternal mortality in developing countries. ${ }^{2}$ Placenta previa is one of the most common causes of obstetrical bleeding and its incidence varies widely

Please cite this paper as: Ali MK, Abbas AM, Abdelbadee AY, Shazly SA, AbdelMagied AM. Use of Foley's catheter balloon tamponade to control placental site bleeding resulting from major placenta previa during cesarean section. Proc Obstet Gynecol. 2016;6(3): Article 4 [ 8 p.]. Available from: http://ir.uiowa.edu/pog/. Free full text article.

Corresponding author: Mohammed Khairy Ali, MD, Women's Health Hospital, Assiut, Egypt, m khairy2001@yahoo.com

Financial Disclosure: The authors report no conflict of interest.

Copyright: (c) 2016 Ali et al. This is an open-access article distributed under the terms of the Creative Commons Attribution License, which permits unrestricted use, distribution, and reproduction in any medium, provided the original author and source are credited. 
but it occurs in every 150-250 live births. $^{3}$

$\mathrm{PPH}$ due to placenta previa is usually from the placental bed at the lower uterine segment and it occurs after the placenta separation. Although, nowadays the obstetrician can diagnose placenta previa before delivery, it is still one of the important causes of maternal mortality. ${ }^{4}$ Hysterectomy can be the only effective action to take, although it carries many morbidities for the women especially those with low parity.

Uterine packing can be considered as a line of treatment before performing surgical procedures in $\mathrm{PPH}$ resulting from placental site bleeding. It can save life, avoid laparotomy and save uterus. ${ }^{6}$

Nowadays, the use of intrauterine balloons have been developed and become effective for the control of placental site bleeding not responding to medical treatment. ${ }^{7}$

The 2-way Foley's catheter has many advantages over the gauze packing; first, it allows drainage of blood so no occult bleeding could be accumulated inside the uterus as in uterine gauze, second the removal of the Foley's catheter balloon is easy and not painful, third, the removal of 2-way Foley's catheter could be gradually as a test of its effectiveness before complete removal. ${ }^{8}$

Bakri intrauterine balloon tamponade is used for treatment of obstetric hemorrhage during cesarean delivery and many recent reports had described the successful use of balloon tamponade to manage hemorrhage due to placenta previa-accreta with an overall success rate of $80 \% .{ }^{9}$ However; its price is expensive so in our country its availability and use is difficult.

With these advantages in our mind, we conducted a six month study of uterine tamponade with 2-way Foley's catheter for treatment of placental site bleeding due to major placenta previa during cesarean section. Hemostasis was adequately achieved after the insertion of the 2-way Foley's catheter balloons and no further invasive surgical procedures were required.

\section{Methods}

The current study is a clinically registered trial (NCT02640885). It was conducted between May and November 2015. The ethical review board of the Faculty of Medicine of the Assiut University approved the study. All women with antepartum hemorrhage who were admitted at our hospital in this period were invited to participate in our study.

The recruited women were screened including history of age, parity, gestational age and history of uterine scar (including CS). A physical examination was done to assess fundal level and uterine tenderness. Finally; all patients were subjected to ultrasound examination (transabdominal and transvaginal) to assess the pregnancy state and diagnose placenta previa. Placenta previa was diagnosed when the placenta is inserted wholly or in part into the lower segment of the uterus and placenta previa considered major if the placenta lies over the internal cervical os. ${ }^{6}$ 
The women who were diagnosed as major placenta previa with gestational age $<32$ weeks were discharged from our hospital after cessation of bleeding. However; patients who were full term pregnancy delivered by elective CS after written consent of hysterectomy and preparation of cross matched blood.

Intra-operatively; all patients were given ecbolic immediately after delivery of the fetus (10 IU oxytocin intramuscular). The patients who did not respond to initial measures (direct uterine massage and ecbolic) were subjected to further management. The 2-way Foley's catheter balloon was inserted vaginally into the uterine cavity. The balloon was positioned to fit the lower uterine segment of the uterus and inflated with $60 \mathrm{~mL}$ of saline.

We applied gentle traction to confirm that the 2-way Foley's catheter balloons were firmly fixed in the lower uterine segment and controlled the placental bed bleeding. The incision of the cesarean section was carefully sutured in treated patients with Vicryl R 1-0 without including the balloons. All cases received broad-spectrum antibiotic systematically used just before the operation and two days after. The blood drainage was collected from 2-way Foley's catheter balloons through the collecting bag. The 2-way Foley's catheter balloons were removed gradually after 24 hours of the operation.

Clinical data were collected together with data on age, parity, gestational age, estimated blood loss, volume of blood transfused and postoperative febrile morbidity.

\section{Results}

One hundred sixty women with antepartum hemorrhage were initially screened. Of these, 53 cases were finally diagnosed with major placenta previa. Fifteen women were discharged from the hospital after cessation of bleeding due to prematurity of the fetus with advice of regular follow up in our outpatient high care unit. The remaining 38 patients were full term pregnancy and delivered by elective cesarean section.

Intra-operatively, 18 patients had limited bleeding from the placental site and responded immediately to ecbolics, however; the remaining 20 patients did not respond to ecbolics. Of those 20 patients, 3 patients required hysterectomy due to placenta accreta. The remaining seventeen patients had severe postpartum hemorrhage which did not respond to medical treatment which included intravenous infusions of oxytocin $\quad(10-20 \quad U)$, intravenous ergometrine $(1 \mathrm{mg})$ and rectal insertion of misoprostol (800 mg). The 2-way Foley's catheter was inserted vaginally into the uterine cavity of the seventeen patients during the cesarean section. However, the placental site continued to bleed in 2 patients out of 17 in spite of Foley's catheter application so immediate peripartum hysterectomy was done. Figure 1 shows the study flow chart. 


\section{0 women were screened in the initial phase of the study}

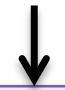

53 cases were finally diagnosed as major placenta previa

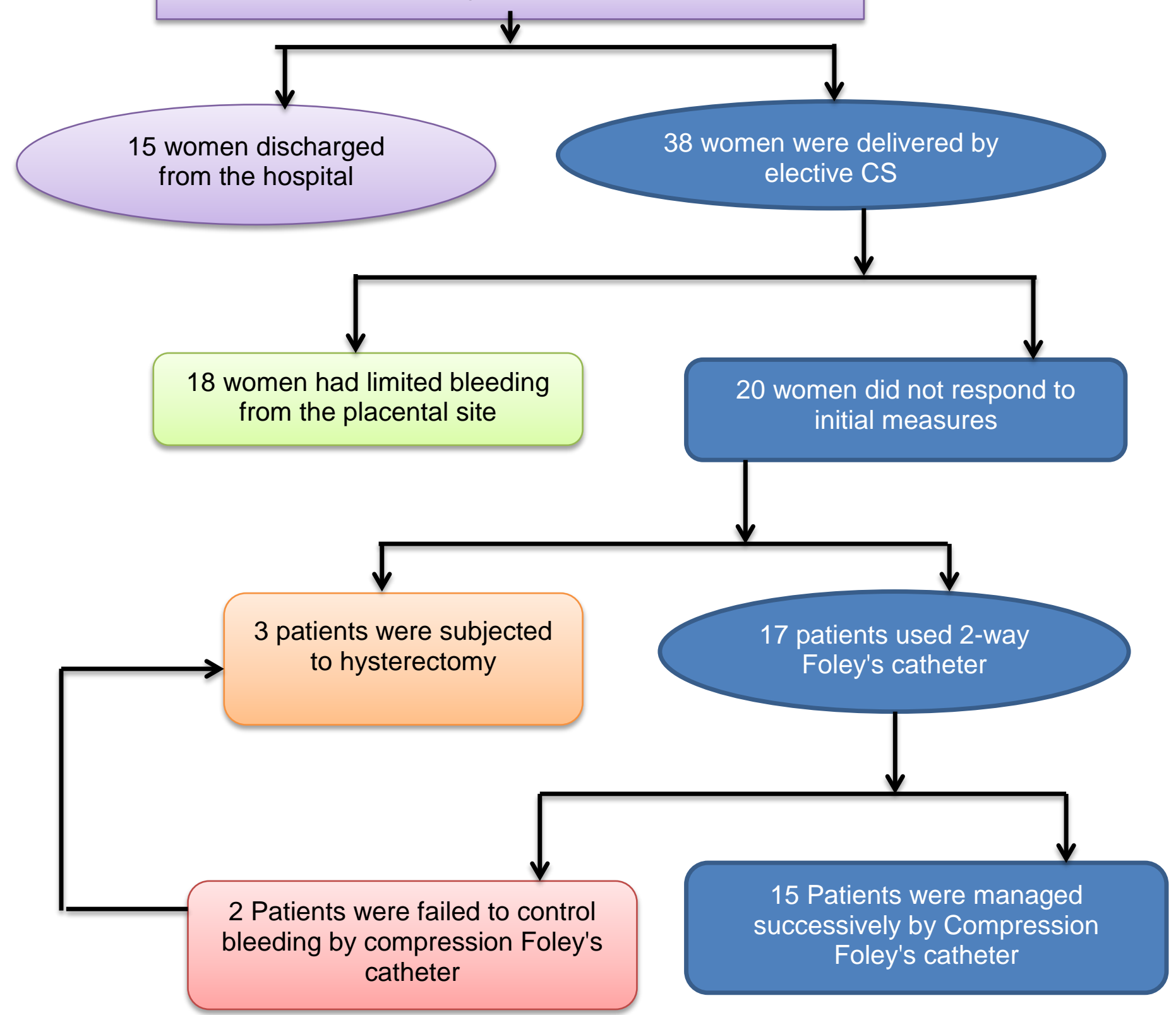

Figure 1: The study flow chart 
Table 1. Summary of the demographic and clinical data of study population

\begin{tabular}{|l|c|c|c|}
\hline & $\begin{array}{c}\text { Patients who did } \\
\text { not respond to } \\
\text { initial measures } \\
(\mathbf{n}=\mathbf{2 0})\end{array}$ & $\begin{array}{c}\text { Patients who were managed } \\
\text { successfully by compression } \\
\text { Foley's catheter } \\
(\mathbf{n}=\mathbf{1 5})\end{array}$ & $\begin{array}{c}\text { Patients in whom } \\
\text { hysterectomy was } \\
\text { indicated } \\
(\mathbf{n}=\mathbf{5})^{*}\end{array}$ \\
\hline Age (years \pm SD) & $26.40( \pm 2.5)$ & $26.13( \pm 2.67)$ & $27.54( \pm 1.92)$ \\
\hline Parity ( \pm SD) & $1.55( \pm 1.05)$ & $1.53( \pm 1.13)$ & $1.8( \pm 0.89)$ \\
\hline $\begin{array}{l}\text { Gestational age } \\
\text { (in weeks } \pm \text { SD) }\end{array}$ & $37.35( \pm 1.09)$ & $37.27( \pm 1.1)$ & $37.8( \pm 1.14)$ \\
\hline Previous uterine scar & $3(15 \%)$ & $1 * *(6.7 \%)$ & $2^{* * *}(40 \%)$ \\
\hline $\begin{array}{l}\text { Position of the placenta } \\
\text { Anterior } \\
\text { Posterior }\end{array}$ & $14(70 \%)$ & $9(60 \%)$ & $3(60 \%)$ \\
\hline Diagnosis of placenta accreta & $6(30 \%)$ & $6(40 \%)$ & $2(40 \%)$ \\
\hline
\end{tabular}

$S D=$ standard deviation

*Those 5 patients included 3 patients who primary subjected to hysterectomy and 2 patients did not respond to Foley's catheter tamponade and subjected to hysterectomy.

** 1 case (The patient had previous 2 Cesarean sections).

*** 2 cases (both had previous 1 Cesarean section).

The demographic and clinical data of those patients are summarized in Table 1. The median age of the women was 26.13 ( \pm 2.67) years. The median gestational age was 37.27 ( \pm 1.1 ) weeks of gestation. The median of the parity was $1.53 \quad( \pm$ 1.13). Complete hemostasis was found in 15 cases $(88.2 \%)$. The drainage blood was continuously monitored until the next day after the operation. The median drainage blood until the next morning was 122.5 ( \pm 92.6). The median bleeding during the operation was $1046.67( \pm 203.1) \mathrm{mL}$. The median of packed RBCs transfusion was 2.33 units $( \pm 0.72)$ and for fresh frozen plasma was 0.53 units $( \pm 0.64)$. Four cases experienced postoperative fever. There were no severe adverse events in any case and no further invasive surgical procedures were required. Table 2 shows the clinical outcomes among the treatment options.

\section{Discussion}

Antepartum hemorrhage remains the most common cause of postpartum hemorrhage. ${ }^{10}$ Placenta previa is a serious obstetric complication. Many treatment options are available for control of bleeding from the placental bed include medical treatment using oxytocin, ergometrine, and misoprostol.

However, with intractable bleeding after failure of medical treatments, surgical intervention is needed. ${ }^{11}$ It includes uterine devascularization followed by uterine compression sutures and finally if failed, hysterectomy is the solution. However, with a low parity woman who has not completed her family, the 
hysterectomy will result in psychological and cultural problems, so it should be avoided whenever possible. While many surgical techniques had been done to avoid hysterectomy, a suitable conservative technique without risk still lacking. ${ }^{12}$

Table 2. Summary of Intra- and postoperative details of study population

\begin{tabular}{|l|c|c|c|}
\hline & $\begin{array}{c}\text { All patients } \\
\mathbf{( n = 2 0 )}\end{array}$ & $\begin{array}{c}\text { Patients who were } \\
\text { managed successfully } \\
\text { by compression Foley's } \\
\text { catheter } \\
\mathbf{( n = 1 5 )}\end{array}$ & $\begin{array}{c}\text { Patients in whom } \\
\text { hysterectomy } \\
\text { was indicated } \\
\mathbf{( n = 5 ) *}\end{array}$ \\
\hline Estimated blood loss (mL) & $1522.5( \pm 619.29)$ & $\begin{array}{c}1046.67( \pm 203.07) \\
\text { plus }\end{array}$ & $2460( \pm 421.9)$ \\
\hline $\begin{array}{c}\text { Transfusions given } \\
\text { Packed RBCs } \\
\text { Fresh frozen plasma }\end{array}$ & 3 units $( \pm 1.41)$ & 2.33 units \pm 0.72 & 5 units \pm 1.00 \\
\hline $\begin{array}{l}\text { Postoperative outcome } \\
\text { Fever (> 37.2 } \\
\text { Evident } \mathbf{C} \text { infection } \\
\text { Secondary postpartum hemorrhage }\end{array}$ & 0.9 units $( \pm 0.912)$ & 0.53 units \pm 0.64 & 2 units \pm 0.707 \\
\hline
\end{tabular}

*Those 5 patients included 3 patients who primary subjected to hysterectomy and 2 patients did not respond to Foley's catheter tamponade and subjected to hysterectomy.

** Drainage blood loss through the catheter.

Nowadays, the use of uterine gauze packing in the management of $\mathrm{PPH}$ secondary to placenta previa becomes not favorable due to many disadvantages like concealing hemorrhage and development of infection. ${ }^{13}$ Control of $\mathrm{PPH}$ by uterine balloon packing itself is not a new technique. Many obstetricians used balloons tamponade like the Rusch balloon and the condom catheter which were effective but they did not allow blood drainage from the uterine cavity. ${ }^{14}$
The Bakri balloon tamponade (BBT) has been used to control uterine bleeding by creating positive pressure inside the lower uterine segment in cases of placenta previa. It is simple and has an $80-100 \%$ success rate. ${ }^{15}$ Because of its high price; it's used only in certain places with limited availability.

However; the 2-way Foley's catheter is so economic (1.5 EP) compared to Bakri balloon (1300 EP) tamponade with a similar success rate $(88 \%)$. Also the blood drainage is collected into a 
collection bag like Bakri balloon, which prevents blood collection inside the uterine cavity that may lead to uterine atony and provide an accurate estimation of bleeding. In addition, with use of 2-way Foley's catheter, we can observe the intraoperative bleeding and if the procedure fails to stop the placental bed bleeding, the failure is immediately visible so it may just slow the bleeding until a definitive procedure done.

With these reasons, the 2-way Foley's catheter may be as effective as other treatment options such as uterine gauze packing or other conventional balloon tamponade. Foley catheter balloon tamponade is easy to perform, effective, cheap and widely available. However, the 2-way Foley's catheter has some disadvantages that include slippage through a dilated cervix but it is unlikely in our patients as cervical dilatation is usually minimal, also rupture of the balloon may be noticed and finally, the small capacity of the Foley's catheter balloon may be another limitation. ${ }^{12}$

\section{Conclusion}

We recommend using the 2-way Foley balloon tamponade as an option in the management of PPH resulting from placenta previa at cesarean delivery prior to any surgical intervention. We appreciate the effectiveness of the 2way Foley balloon and we emphasize that the efficacy of Foley catheter balloon tamponade should not be underestimated.

\section{References}

1. Garabedian C, Simon M, Closset E, Ducloy-Bouthors AS, Schaffar A, Deruelle P, Gautier S, Depret S, Subtil D. Systematic prophylactic oxytocin injection and the incidence of postpartum hemorrhage: A before-andafter study. J Gynecol Obstet Biol Reprod (Paris). 2016 Feb;45(2):147-54. http://dx.doi.org/10.1016/j.jgyn.2015.11. 005 Epub 2015 Dec 30. PubMed PMID: 26747233.

2. Goffman D, Nathan L, Chazotte C. Obstetric hemorrhage: A global review. Semin Perinatol. 2016 Mar;40(2):96-8. http://dx.doi.org/10.1053/i.semperi.2015. 11.014 Epub 2015 Dec 29. PubMed PMID: 26742599.

3. Prata N. Prevention of postpartum haemorrhage at community level: which uterotonic? Lancet Glob Health. 2016 Jan;4(1):e4-5.

http://dx.doi.org/10.1016/S2214109X(15)00297-1 PubMed PMID: 26718809.

4. Pendleton $A A$, Natarajan $A$, Ahn $R$, Nelson BD, Eckardt MJ, Burke TF. Emergency hysterectomy for uncontrolled postpartum hemorrhage may be averted through uterine balloon tamponade in Kenya and Senegal. Int J Gynaecol Obstet. 2015 Dec 11. pii: S0020-7292(15)00717-1.

http://dx.doi.org/10.1016/j.ijgo.2015.09.0 06 [Epub ahead of print] PubMed PMID: 26797194.

5. Qiao XM, Bai L, Li H, Zhu F. Vaginal bilateral cervical lips suture in combination with intrauterine Foley catheter to arrest postpartum hemorrhage. Clin Exp Obstet Gynecol. 2015;42(2):191-4. PubMed PMID: 26054117. 
6. Royal College of Obstetricians and Gynaecologists. Prevention and management of postpartum hemorrhage. Green-top Guideline No. 52 .London RCOG; 2011 https://www.rcog.org.uk/en/guidelinesresearch-services/guidelines/gtg52/

7. Frenzel D, Condous GS, Papageorghiou AT, McWhinney NA. The use of the "tamponade test" to stop massive obstetric haemorrhage in placenta accreta. BJOG. 2005 May;112(5):676-7. http://dx.doi.org/10.1111/j.14710528.2005.00491.x PubMed PMID: 15842298.

8. Bagga R, Jain V, Kalra J, Chopra S, Gopalan S. Uterovaginal packing with rolled gauze in postpartum hemorrhage. MedGenMed. 2004 Feb 13;6(1):50. PubMed PMID: 15208561.

9. Bakri YN, Amri A, Abdul Jabbar F. Tamponade-balloon for obstetrical bleeding. Int J Gynaecol Obstet. 2001 Aug;74(2):139-42. http://dx.doi.org/10.1016/S00207292(01)00395-2 PubMed PMID: 11502292.

10. Høj L, da Silva D, Hedegaard K, Sandström A, Aaby P. Maternal mortality: only 42 days? BJOG. 2003 Nov;110(11):995-1000. http://dx.doi.org/10.1016/S14700328(03)03907-7 PubMed PMID: 14592584.
11. Cho HY, Park YW, Kim YH, Jung I, Kwon JY. Efficacy of Intrauterine Bakri Balloon Tamponade in Cesarean Section for Placenta Previa Patients. PLoS One. 2015 Aug 11;10(8):e0134282. http://dx.doi.org/10.1371/journal.pone.01 34282 eCollection 2015. PubMed PMID: 26263014

12. Dildy GA 3rd. Postpartum hemorrhage: new management options. Clin Obstet Gynecol. 2002 Jun;45(2):330-44. http://dx.doi.org/10.1097/00003081200206000-00005 PubMed PMID: 12048393.

13. Chandraharan E, Arulkumaran S. Surgical aspects of postpartum haemorrhage. Best Pract Res Clin Obstet Gynaecol. 2008 Dec;22(6):1089102.

http://dx.doi.org/10.1016/j.bpobgyn.2008 .08.001 Epub 2008 Sep 14. PubMed PMID: 18790675.

14. Vitthala S, Tsoumpou I, Anjum ZK, Aziz NA. Use of Bakri balloon in post-partum haemorrhage: a series of 15 cases. Aust N Z J Obstet Gynaecol. 2009 Apr;49(2):191-4. http://dx.doi.org/10.1111/i.1479828X.2009.00968.x PubMed PMID: 19432609.

15. Alkış I, Karaman E, Han A, Ark HC, Büyükkaya $B$. The fertility sparing management of postpartum hemorrhage: A series of 47 cases of Bakri balloon tamponade. Taiwan J Obstet Gynecol. 2015 Jun;54(3):232-5. http://dx.doi.org/10.1016/.tjog.2014.03.0 09 PubMed PMID: 26166332. 